\title{
Efektivitas Perendaman Serat Aren dan Endosperm Kelapa Terhadap Pertumbuhan dan Hasil Tomat Pada Hidroponik Substrat
}

\author{
Dwi Harjoko1), Sulandjari1), Yuni Kusniyawati²)
}

\begin{abstract}
This study was conducted to determine the effect of soaking period of arenga fibers and the addition of coconut endosperm to growth and yield of tomatoe. The observations were analyzed by using the $5 \% \mathrm{~F}$ test and if significant continued by the 5\% DMRT. The experiment was conducted using a completely randomized factorial design with two factors, factors substrate consists of 5 levels, fiber arenga without soaking (S0), fiber soaking for 1 month (S1), fiber soaking for 2 months (S2), fiber soaking for 3 months(S3), and substrate husk as control. The second factor is a nutrient with two levels ie. $A B$ mix nutrient (N1), $A B$ mix nutrient plus $50 \%$ coconut endosperm (N2). The results showed that treatment of arenga fiber substrate by immersion of one month, 2 month, and 3 month not significantly influenced on all growth variable and yield of tomato. Treatment spraying coconut endosperm with a concentration of $50 \%$ could be low variable root length, root volume and fresh weight of the plant. There was no interaction between the two factors of all the observed variables.
\end{abstract}

Keywords : tomatoes, soiless culture, arenga fiber, soaking time, coconut endosperm

\section{PENDAHULUAN}

Tomat (Lycopersicum esculentum) merupakan salah satu komoditas yang dianggap penting didunia dan yang berasal dari keluarga Solanaceae (Arthur et al. 2015). Saat ini tomat dikonsumsi pada tingkat yang lebih tinggi di negara- negara maju dari pada di Negara berkembang oleh karena itu tomat juga disebut sebagai komoditas mewah (Sakthivel et al. 2015). Produksi hortikultura di sebagian besar daerah tropis sangat sulit karena tingginya tingkat infeksi oleh penyakit yang tersimpan ditanah (Wahome et al. 2011). Salah satu upaya untuk meningkatkan produksi tomat secara kontiyu adalah dengan menggunakan teknologi hidroponik. Hidroponik menjadi alternative yang paling baik sebagai budidaya tanaman tanpa tanah yang saat ini bnyak di terapkan secara komersial di negara-negara barat (Mugundhan 2011).

Sistem budidaya secara hidroponik, penggunaan media kultur merupakan salah satu kunci yang harus diperhatikan untuk menjamin keberhasilan tehnik ini, penggunaan media yang tidak sesuai standar akan membatasi perolehan larutan hara yang dapat mempengaruhi

\footnotetext{
1)Lecturer Staff of Study Program of Agrotechnology, Faculty of Agriculture, Sebelas Maret University (UNS) on Surakarta.

2) Undergraduate Student of Study Program of Agrotechnology, Faculty of Agriculture, Sebelas Maret University (UNS) on Surakarta.

Contact Author: Yunikusniyawati@yahoo.com
}

pertumbuhan tanaman (Radhouani et al. 2011). Penelitian terkait juga dilakukan oleh Shirani et al. (2013) dalam penelitiannya bahwa kualitas media sangat mempengaruhi kualitas buah, media kultur yang baik mengandung kedua sifat fisika dan kimia yang dapat mendukung kesehatan buah terutama teknik budidaya tanpa tanah dalam green house.

Media tanam organik menjadi alternatif media yang yang lebih menjanjikan dan kompetitif dari pada media an organik. Media ini memungkinkan tanaman untuk dapat mengakses nutrisi yang berada dalam batas kritis (Olle 2012). Media tanam dalam hidroponik substrat salah satunya dengan serat aren.

Keberhasilan budidaya secara hidroponik sederhana, selain ditentukan oleh medium juga ditentukan oleh nutrisi (Silvina dan Syafrinal 2008). Air kelapa mengandung hormon pertumbuhan, berbagai macam mineral dan vitamin yang penting untuk pertumbuhan tanaman (Oka 2014). Berdasarkan hal tersebut, penelitian ini dilakukan bertujuan untuk mengetahui seberapa besar pengaruh lama perendaman serat aren dan penambahan nutrisi organik air kelapa terhadap pertumbuhan tanaman dan hasil panen tomat.

\section{METODE PENELITIAN}

Penelitian ini dilaksanakan mulai bulan Maret 2015 sampai bulan Desember 2015 bertempat di Screen House B, Fakultas Pertanian, Universitas Sebelas Maret, Surakarta. Alat yang digunakan dalam penelitian ini adalah gelas ukur, EC meter, $\mathrm{pH}$ meter, timbangan analitik, mesin penggiling serat, drum air, polibag ukuran $30 \times 35 \mathrm{~cm}$, sprayer, jangka sorong, ajir, 
dan meteran. Bibit tanaman tomat (Lycopersicum esculentum) New Sutisna F1, limbah serat aren tanpa perendaman dan yang telah direndam, arang sekam, nutrisi $A B$ mix dan air kelapa.

Penelitian dilaksanakan dengan menggunakan rancangan acak lengkap (RAL) faktorial dengan 2 faktor yaitu, faktor substrat tanam terdiri atas 5 taraf yaitu A1: substrat arang sekam, S0: serat aren tanpa direndam, S1: serat aren perendaman 1 bulan, S2: serat aren perendaman 2 bulan, S3: serat aren perendaman 3 bulan. Faktor kedua adalah nutrisi dengan 2 taraf yaitu N1: nutrisi $A B$ mix, N2: nutrisi $A B$ mix ditambah campuran air kelapa dengan konsentrasi 50\%. Masing-masing perlakuan diulang 3 kali. Data hasil pengamatan diuji dengan menggunakan uji $F$ taraf $5 \%$. Apabila signifikan maka dilanjutkan dengan DMRT taraf $5 \%$.

\section{HASIL DAN PEMBAHASAN}

\section{Tinggi Tanaman}

Data hasil pengamatan tinggi tanaman setelah di uji anova menunjukkan bahwa perlakuan substrat berpengaruh nyata terhadap pertambahan tinggi tanaman tomat, sedangkan nutrisi tidak terhadap variabel tinggi tanaman. Tidak terdapat interaksi antara kedua perlakuan terhadap variabel tinggi tanaman.

Berdasarkan Gambar 1. dapat dilihat bahwa rerata perlakuan tertinggi pada 10 MST adalah jenis substrat arang sekam yaitu sebesar $120,5 \mathrm{~cm}$, kemudian diikuti dengan serat aren yang direndam selama 3 bulan dengan rata-rata tinggi tanaman $102 \mathrm{~cm}$, dan pada perlakuan serat aren yang tanpa direndam, direndam 1 bulan, dan 2 bulan tidak menunjukkan perbedaan yang signifikan. Dan untuk semua substrat serat aren menunjukkan perbedaan terhadap perlakuan kontrol. Kemampuan media tersebut untuk menahan air dan memberikan aerasi dan drainase yang baik, apabila tanaman tidak mendapatkan hara yang sesuai kebutuhan akan maka pertumbuhannya akan terhambat, hal tersebut juga akan berpengaruh terhadap tinggi tanaman.

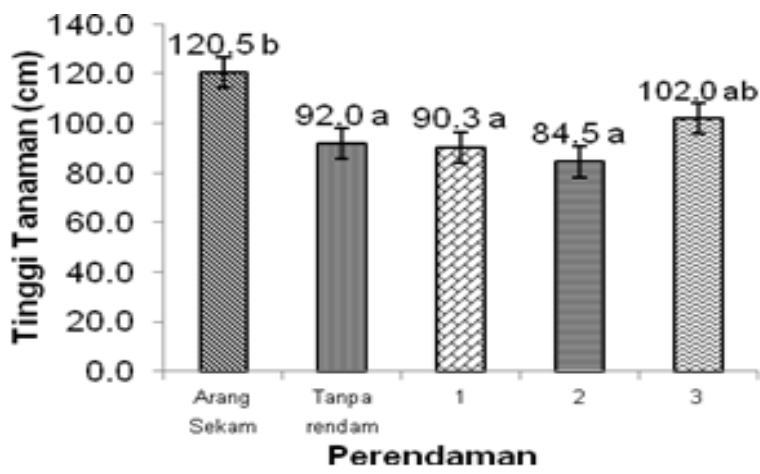

Gambar 1. Pengaruh perendaman serat aren terhadap tinggi tanaman

\section{Kadar Klorofil}

Pengukuran karakter fisiologi seperti kandungan klorofil, merupakan salah satu pendekatan untuk mengetahui pengaruh kekurangan air terhadap pertumbuhan dan hasil, dan parameter ini berkaitan erat dengan laju fotosintesis (Li 2006). Hasil anova menunjukkan perlakuan substrat memberikan pengaruh terhadap variabel kadar klorofil daun, dan tidak terdapat interaksi antara kedua perlakuan dengan variabel klorofil daun. Pada Gambar 2. dapat kita ketahui bahwa nilai rata-rata kadar klorofil teringgi terdapat pada perlakuan substrat arang sekam yaitu 44,4.

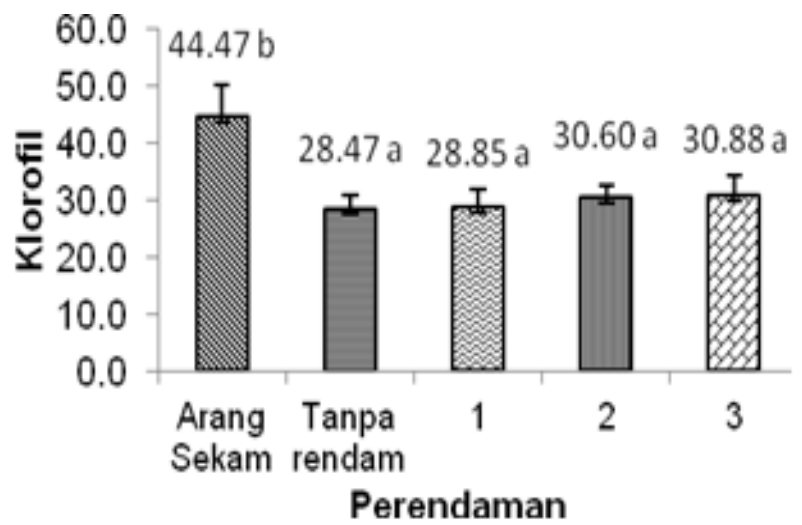

Gambar 2. Pengaruh prendaman serat aren terhadap kadar klorofil daun

Rerata hasil tinggi tanaman pada substrat arang sekam tersebut berbeda nyata dengan perlakuan dengan perlakuan substrat serat aren tanpa rendam, rendam 1 bulan, 2 bulan dan 3 bulan yang berturut- turut sama. Penyerapan nutrisi yang baik akan meningkatkan kadar klorofil pada daun. Hal tersebut didukung oleh pernyataan Elli et al. (2012) bahwa kandungan klorofil menurun diduga karena menurunnya konsentrasi Mg didalam daun. Menurut Savvas (2003) substrat organik yang mudah membusuk 
akan mengubah struktur fisik dan kimianya, sehingga mengakibatkan adanya petukaran ion dan naiknya $\mathrm{pH}$. Ketika $\mathrm{pH}$ substrat naik diatas 6,5 banyak unsure hara mikro ( $\mathrm{Fe}, \mathrm{Mn}, \mathrm{Zn}, \mathrm{Bo})$ yang tidak larut sehingga sulit untuk diserap oleh tanaman. Babaein et al. (2011) menyatakan bahwa aplikasi Fe dan Mn dapat memberikan hasil tertinggi kadar klorofil daun.

\section{Panjang Akar}

Bagi tanaman, akar adalah satu faktor penting bagi pertumbuhan, tanpa akar proses fotosintesis untuk memproduksi karbohidrat dan energi tidak akan bisa berjalan (Mahendra 2009). Perlakuan substrat dan berpengaruh secara signifikan terhadap variabel panjang akar, tetapi tidak terdapat interaksi kedua faktor perlakuan terhadap variabel panjang akar. Pada Gambar 3. Menunjukkan bahwa panjang akar pada media arang sekam menunjukan hasil yang berbeda terhadap semua perlakuan substrat serat dengan nilai rata-rata $44,3 \mathrm{~cm}$, sedangkan rerata terendah pada perlakuan serat aren yang direndam 3 bulan dengan nilai $20,8 \mathrm{~cm}$.

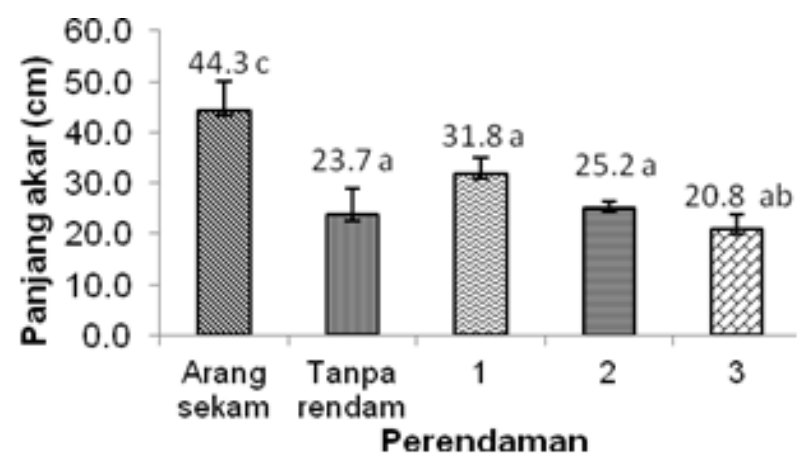

Gambar 3. Pengaruh perendaman serat aren terhadap panjang akar

Pada Gambar 3. bahwa serat aren dengan perendaman 0 bulan dan 1 bulan sangatlah mudah dalam melepaskan nutrisi, oleh karena itu akar tanaman tumbuh lebih panjang untuk mempertahankan daya hidupnya dalam memasok unsur hara. Hal tersebut didukung oleh pernyataan, Sitompul dan Guritno (1995) bahwa hubungan akar dengan tajuk mula-mula lebih banyak ditekankan dari segi morfogenetik seperti dalam pandangan semakin banyak akar semakin baik hasil tanaman. Tetapi tanaman yang tumbuh dalam keadaan kurang air akan membentuk akar yang lebih panjang dengan hasil yang lebih rendah dari tanaman yang tumbuh dalam cukup air.

Gambar 4. Terlihat bahwa tanaman tanpa penambahan air kelapa memiliki akar yang lebih panjang dibandingkan dengan penambahan air kelapa dengan nilai 33,1 cm. Jamur akan membuat media substrat serat aren semakin cepat melapuk akibatnya kemapuan media untuk menopang dan menyediakan tempat tumbuh bagi tanaman juga akan menurun. Air kelapa secara alami mengandung hormon alami yaitu diantaranya kelompok sitokinin. Sitokinin dapat mengambat pembentukan akar dan mendorong pembentukan klorofil (Surachman 2011).

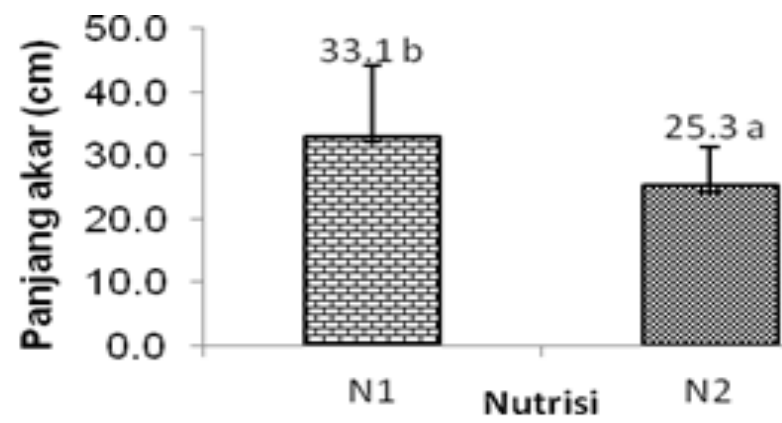

Keterangan :

$\mathrm{N} 1: \mathrm{AB}$ mix

$\mathrm{N} 2: \mathrm{AB}$ mix + Air kelapa

Gambar 4. Pengaruh nutrisi terhadap panjang akar tanaman tomat

\section{Volume Akar}

Volume akar dipengaruhi oleh tingkat distribusi akar dan ketersediaan hara dan air. Akar yang tersebar dan didukung oleh air dan hara yang cukup akan meningkatkan volume akar. Perlakuan substrat dan nutrisi berpengaruh secara signifikan terhadap variabel volume akar, tetapi tidak terjadi interaksi kedua faktor terhadap variabel volume akar. Gambar 5. Menunjukkan rerata volume akar tertinggi terdapat pada tomat yang ditanam pada substrat arang sekam dengan nilai rerata $55 \mathrm{ml}$ kemudian disusul dengan tanaman yang di tanam pada serat aren yang direndam selama 3 bulan sebesar 20,8 ml.

Serat batang aren memiliki pori makro yang banyak sehingga nutrisi yang disiramkan lebih banyak yang lolos dari yang ditahan oleh substrat bahkan nutrisi yang diberikan banyak yang menggenang pada dasar polibag, hal tersebut inilah yang menyebabkan akar tanaman rusak dan busuk karena tergenang. Lutfyrachman et al. (2013) menyatakan bahwa tanaman tomat membutuhkan air yang banyak, namun tidak dalam jumlah berlebihan, akar tanaman tomat tidak mampu berfungsi dengan baik pada keadaan yang tergenang hal ini dapat menyebabkan pertumbuhan tanaman terhambat. Menurut Sahin et al. (2002) jumlah ruang pori substrat merupakan karakteristik fisik yang penting yang mempengaruhi penyerapan air dan nutrisi dan pertukaran gas pada sistem perakaran. 


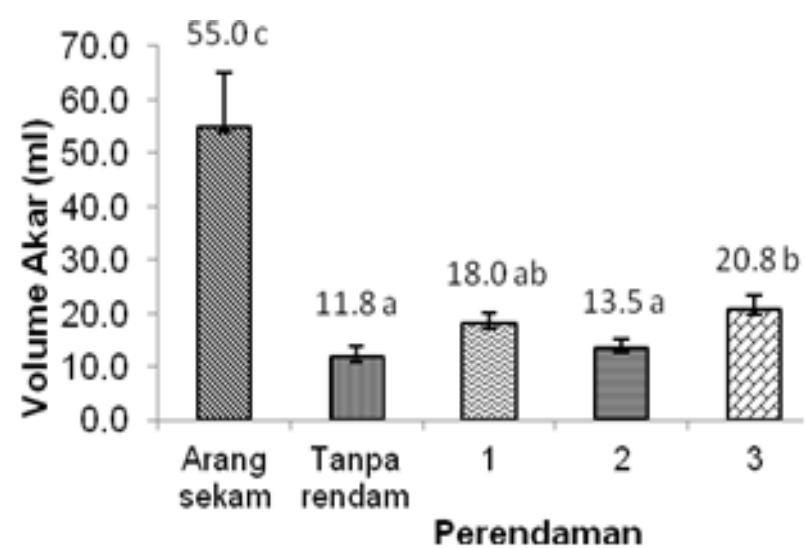

Gambar 5. Pengaruh perendaman serat aren terhadap volume akar

Pada Gambar 6. perlakuan nutrisi terdapat perbedaan secara signifikan terhadap volume akar. Tanaman pada perlakuan penambahan air kelapa menghasilkan volume akar yang lebih rendah dibandingkan tanpa penambahan air kelapa. Penyemprotan air kelapa yang jatuh dalam media terutama serat aren akan cepat menumbuhkan jamur. Menurut Saraswati (2008) fungi terdapat di setiap tempat terutama di darat dalam berbagai bentuk, ukuran, dan warna. Pada umumnya mempunyai kemampuan yang lebih baik dibanding bakteri dalam mengurai sisa-sisa tanaman (hemiselulosa, selulosa, dan lignin).

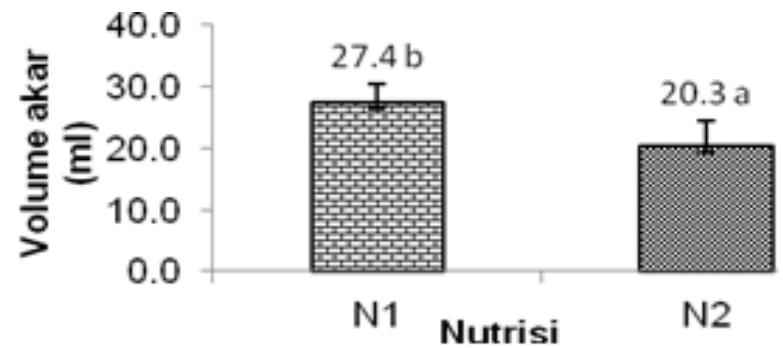

Keterangan :

$\mathrm{N} 1: \mathrm{AB}$ mix

$\mathrm{N} 2: \mathrm{AB}$ mix + Air kelapa

Gambar 6. Pengaruh nutrisi terhadap volume akar tanaman tomat

\section{Berat Kering Tanaman}

Pengukuran biomassa total tanaman merupakan parameter yang paling baik digunakan sebagai indikator pertumbuhan tanaman, alasan pokok lain dalam penggunaan biomassa total tanaman adalah bahwa bahan kering tanaman dipandang sebagai manivestasi dari semua proses dan peristiwa yang terjadi dalam pertumbuhan tanaman. Karena itu parameter ini dapat digunakan sebagai ukuran global pertumbuhan tanaman dengan segala peristiwa yang dialaminya (Sitompul dan Guritno 1995). Hasil analisis ragam diketahui bahwa tidak ada interaksi antara substrat dengan nutrisi pada variable berat kering tanaman. Pada Gambar 7. diatas dapat diketahui bahwa rerata tertinggi terdapat pada perlakuan dengan substrat arang sekam (kontrol) dengan nilai rerata $62,68 \mathrm{~g}$, nilai tersebut berbeda secara signifikan terhadap substrat serat aren pada berbagai perlakuan dengan nilai yang lebih rendah pada semua perlakuan.

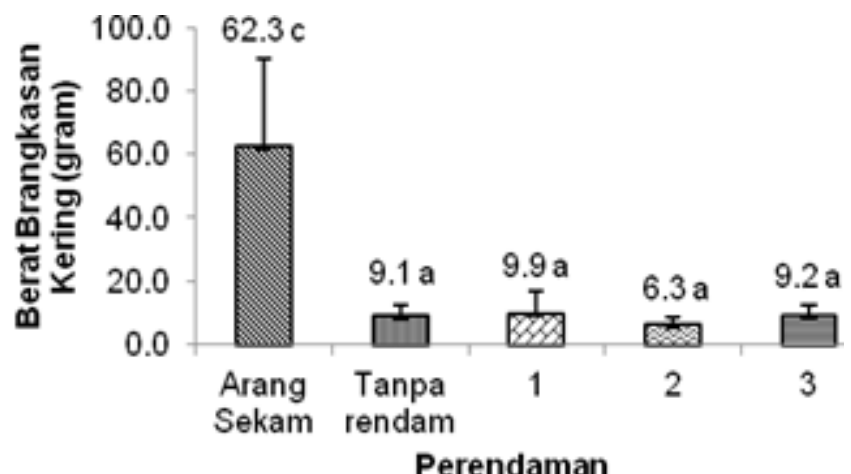

Gambar 7. Pengaruh perendaman serat aren terhadap berat kering tanaman tomat

Pada media serat aren mempunyai nilai $\mathrm{pH}$ yang tinggi di bandingkan arang sekam. Menurut Jones (2008) dalam Lutfyrachman et al. (2013) tanaman tomat tumbuh baik pada tanah dengan ph 5,5 sampai 6,8 . Pada $\mathrm{pH}$ optimal, hara esensial akan tersedia dalam jumlah yang optimal. Berkurangnya tinggi tanaman, daun yang terbentuk menjadi lebih sedikit sehingga pembentukan karbohidrat hasil asimilasi tanaman juga menurun, yang akan menyebabkan penurunan berat basah tanaman serta berat kering tanaman.

\section{Berat Akumulasi Buah Tomat}

Berat buah merupakan variabel pengamatan yang penting karena merupakan hasil penyimpanan fotosintat dalam bentuk buah dan merupakan indikator untuk menentukan berapa hasil atau produksi buah yang dihasilkan tanaman. Hasil anova taraf 5\% menunjukkan bahwa tidak terjadi interaksi antara media dan nutrisi yang diberikan. Gambar 8. diatas menunjukkan bahwa pada media serat aren mempunyai rerata yang paling tinggi dengan nilai $388,0 \mathrm{gr}$ dan hasil terendah pada perlakuan media serat aren yang direndam 1 bulan dengan nilai $155,0 \mathrm{gr}$. 


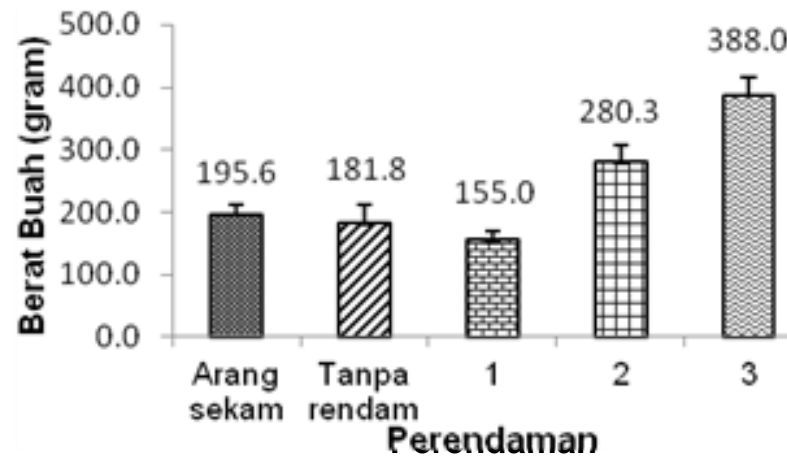

Gambar 8. Pengaruh Perendaman serat aren terhadap akumulasi berat buah tanaman tomat

Pada media serat aren yang direndam 3 bulan mempunyai akumulasi berat buah yang tinggi dikarenakan setiap panen pada perlakuan tersebut selalu meningkat. Pada media arang sekam hasilnya lebih rendah karena hasil fotosintat lebih banyak digunakan untuk pertumbuhan vegetative. Derajat keasaman sangat mempengaruhi pembentukan dan kualitas buah. Nemr (2012) menyatakan bahwa konsentrasi K. pada media dapat meningkatkan hasil dan kualitas buah tomat. Substrat serat aren mempunyai $\mathrm{pH}$ yang tinggi dibandingkan arang sekam sehingga pembentukan buah berjalan optimal karena unsur hara yang dibutuhkan untuk pembentukan buah tersedia.

\section{KESIMPULAN DAN SARAN}

\section{Kesimpulan}

Berdasarkan hasil penelitian maka dapat disimpulkan sebagai berikut:

1. Perlakuan substrat serat aren tanpa perendaman, serat aren yang direndam selama 1 bulan, 2 bulan dan 3 bulan tidak berpengaruh secara signifikan terhadap variabel pengamatan pertumbuhan dan hasil tomat.

2. Perlakuan penyemprotan air kelapa dengan konsentrasi $50 \%$ secara signifikan dapat menurunkan variabel panjang akar, volume akar dan berat segar tanaman.

3. Tidak terdapat interaksi faktor lama perendaman substrat serat aren dan penyemprotan air kelapa terhadap semua variabel pertumbuhan dan hasil tomat.

\section{Saran}

Saran yang diberikan dalam penelitian ini adalah penggunaan substrat serat aren sebaiknya di campur dengan substrat lain terutama media anorganik yang mempunyai massa yang lebih berat agar mampu mendukung tumbuh tegaknya tanaman dan mempunyai aerasi dan drainase yang bagus bila kedua substrat dikombinasikan. Hal tersebut dikarenakan jika serat aren digunakan sebagai media tanpa campuran media lain tanam nutrisi yang diberikan akan cepat lolos sehingga kebutuhan nutrisi tanaman kurang tercukupi dan substrat ini juga kurang mampu mendukung tumbuh tegaknya tanaman.

\section{DAFTAR PUSTAKA}

Arthur, E., Oduro, I., Kumah, P. 2015, Postharvest quality response of tomato (Lycopersicon esculentum, Mill) fruits to different concentrations of calcium chloride at different dip- times, Am J Food Nutr, 5(1) : 1-8, DOI: 10.5251/ajfn.2015.5.1.1.8.

Babaein, M., Issa, P., Abolfazl, T., Yasser, E., Hossein, G. 2011, Effect of water stress and micronutrients ( $\mathrm{Fe}, \mathrm{Zn}$ and $\mathrm{Mn})$ on chlorophyll fluorescence, leaf chlorophyll content and sunflower nutrient uptake in Sistan region, Afr J Agric Res, 6(15) : 35263531, DOI: 10.5897/AJAR10.1142.

Elly, P., Irfan, DP., Diah, R., Retno, PS. 2012, Laju fotosintesis dan kandungan klorofil kedelai pada media tanam masam dengan pemberian garam alumunium, Agrotop, 2(1) : 17-24, URL : http:// download. Portal garuda.org /article.php ?article= $72052 \& \mathrm{val}=924$.

Guritno, B., Sitompul, SM. 1995, Analisis Pertumbuhan Tanaman, Yogyakarta : Gadjah Mada University Press.

Li, R., Guo, P., Baum, M., Grando, S., Ceccareli, S. 2006, Evaluation of chlorophyll content and flouresence parameters as indicators of drought tolerance in barley, Agric Sci China, 5(10) : 751-757, DOI: 10.1016/S16712927(06)60120-X.

Lutfyrachman, H., Anas, DS. 2013, Optimasi dosis pupuk anorganik dan pupuk kandang ayam pada budidaya tomat hibrida (Lycopersicon esculentum Mill), Bul Agrohorti, 1(1) : 119-126, URL: http:// agrohort .ipb. ac.id/ journal /index. php/agh/article/pdf.

Mahendra, F. 2009, Sistem Agroforetri dan Aplikasinya, Yogyakarta : Graha IImu.

Mugundhan, MR., Soundaria, M., Maheswari, V., Santhakumari, P., Gopal, V. 2011, "Hydroponics"- a novel alternative for geoponic cultivation of medicinal plants and food crops, Intl J Pharm and Bio Sci, 2(2), URL : http:// ijpbs. net/ volume2 /issue2/pharma/38.pdf.

Nemr, M., El-Baky, A., Salman, S., Tohami, W. 2012, Effect of different potassium levels on the growth, yield and quality of tomato grown in sand-ponic culture, Aust $\mathrm{J}$ Basic and App Sci, 6(3) : 779-784, URL: http: // 
ajbasweb. com /old/ ajbas /2012 /March/779-784.pdf

Oka, DN. 2014, Coconut water medium increases the germination power of cucumber (Cucumis sativus $\mathrm{L}$ ) seed and the implementation in dormancy practicum, IJSRE, 2(6) : 1019-1028, URL:http: //ijsae.in/ ijsaeems/ index.php /ijsae /article /view/ 230/179.

Olle, M., Ngouajio, M., Siomos, A. 2012, Vegetable quality and productivity as influenced by growing medium, J Agric, 99(4) : a review, URL : http: //www. Izi. It/ tomai $/ 99 \% 284 \% 29$ tomas/ 4 tomasst $r 9$. pdf.

Radhouani, A., Bekkay, ME., Ferchichi, A. 2011, Effect of substrate on vegetative growth, quantitative and qualitative production of muskmelon (Cucumis melo) conducted in soilless culture, Afr J Agric Res, 6(3) : 578585, DOI :10.5897/AJAR10.124.

Sahin, U., Anapali, O., Ercisli, S. 2002, Physicochemical and physical properties of some susbtrates used in holticultures, Gartenbauwissenschaft 67 : 55-60, DOI : 10.17660/ActaHortic.2004.648.21.

Sakhivel, S., Magnigandan, V. 2011, Tissue culture studies in tomatto (Lycopersicon esculantum, Mill) from cotyledonary leaf explants, Intl J Chem and Pharm, 2(3), URL : http:/ /www. ijcps. com/ files/ vol2issue 3/5.pdf.

Saraswati, Rasti, E., Santosa, Yuniarti, E. 2008 , Organisme perombak bahan organic, URL: http:// balittanah. Litbang .pertanian.go.ld/ind / dokumentasi buku/ pupuk/ pupuk 10. pdf.Diakses tanggal 1 Juni 2016.

Savvas, D. 2013, Hydroponics : A modern technology supporting the application of integrated crop management in greenhouse, J Food Agric Environ, 1(1) : 80-86, URL: www.world-food.net.

Shirani, M., Mohammadi-Ghehsareh, A., Manoukyan, R. 2013, The effect of date palm wastes as a culture media on some nutrient element of tomato fruit, Agric Forest J, 59(1) : 73-84, URL: http: //www .sjournals .com/ index. php/AA/article/view/467.

Silviana, F., Syafrinal. 2008, Penggunaan berbagai medium tanam dan konsentrasi pupuk organik cair pada pertumbuhan dan produksi mentimun jepang secara hidroponik, J Sagu, 7(1) : 7-12, URL:http: //download. portal garuda. Org /article. php? Article $=105910 \& \mathrm{val}=2286$.

Surachman, D. 2011, Teknik pemanfaatan air kelapa untuk perbanyakan nilam secara in vitro, Buletin Teknik Pertanian, (16) : 31-33, URL : http: //pustaka .litbang. pertanian. go.id /publikasi /bt 16 1118.pdf.

Wahome, PK., Oseni, TO., Michael, T., Masarieambi, Shongwe, VD. 2011, Effects of different hydroponics systems and growing media on the vegetative growth, yield and cut flower quality of gypsophila (Gypsophila paniculata L.), World Agric Sci, $7(6)$ : 692-698, URL: http://www. idosi. org /wjas/wjas7(6)/9.pdf. 